\title{
Analisa Efisiensi Termal Water Tube Boiler Berdasarkan Rasio Udara Bahan Bakar LPG Untuk Memproduksi Saturated dan Superheated Steam
}

\author{
Ayuni Lestari*1, Valencia Tara Situmorang ${ }^{2}$, Tahdid $^{3}$, K.A Ridwan ${ }^{4}$, Agus Manggala ${ }^{5}$ \\ 1,2,3,4,5Teknik Energi/Teknik Kimia, Politeknik Negeri Sriwijaya, Indonesia \\ Email: ${ }^{1}$ lestariayuni13@gmail.com, ${ }^{2}$ valenciasitumorang99@gmail.com
}

\begin{abstract}
Abstrak
Boiler adalah suatu bejana tertutup yang terbuat dari baja dan digunakan untuk menghasilkan steam. Agar dapat menghasilkan steam diperlukan pembakaran. Pembakaran merupakan reaksi eksotermis yang berlangsung sangat cepat, yang membebaskan energi berupa panas dan nyala api (flame temperature) serta mampu menyebarkan panas melalui suatu medium. Berdasarkan kekurangan pada penelitian sebelumnya akan dilakukan pengupgradean pada sistem injection Boiler feed Water dan sistem kontrol secondary udara pembakaran. Pada sistem injection boiler feed water dilakukan perubahan sistem pemompaan yang tahan tekanan balik dan tahan panas. Untuk sistem secondary udara pembakaran akan didukung menggunakan blower dan flow meter sehingga laju pemasokan udara akan terkontrol. Selanjutnya yaitu sistem control level ketinggian air pada drum tujuannya agar air didalam akan tenang dan terbaca oleh alat water level gauge saat proses berjalan. Dengan upgrade ketiga sistem tersebut diharapkan proses produksi steam akan dapat berlangsung secara steady state atau kontinyu meningkatkan efisiensi termal water tube boiler. Bahan bakar yang digunakan adalah gas LPG. Oleh karena itu, pada penelitian kali ini akan difokuskan untuk menentukan rasio udara dengan bahan bakar gas yang paling tepat sehingga didapatkan hasil pembakaran dan produksi steam yang maksimal. Rasio udara bahan bakar gas dan excess air yang digunakan yakni, 15,78 (5\%), 15,93 $(6 \%), 16,08(7 \%), 16,23(8 \%), 16,38(9 \%)$.
\end{abstract}

Kata kunci: Boiler, steam, efisiensi, rasio udara bahan bakar.

\section{Analysis Of Thermal Efficiency Water Tube Boiler Based On Lpg Fuel Air Ratio To Produce Saturated And Superheated Steam}

\begin{abstract}
Boiler is a closed vessel made of steel and used to produce steam. In order to produce steam, combustion is required. Combustion is an exothermic reaction that takes place very quickly, which liberates energy in the form of heat and flame (flame temperature) and is able to spread heat through a medium. Based on the shortcomings in the previous research, an upgrade to the Boiler feed Water injection system and the combustion air secondary control system will be carried out. In the injection boiler feed water system, changes are made to the pumping system that is resistant to back pressure and heat resistance. For the secondary combustion air system, it will be supported using a blower and flow meter so that the rate of air supply will be controlled. Next is the water level control system on the drum so that the water inside will be calm and read by the water level gauge when the process is running. By upgrading the three systems, it is expected that the steam production process will be able to take place in a steady state or continuously improve the thermal efficiency of the water tube boiler. The fuel used is LPG gas. Therefore, this research will focus on determining the most appropriate ratio of air to gas fuel so that maximum combustion results and steam production are obtained. The ratio of air fuel gas and excess air used is, $15.78(5 \%), 15.93(6 \%), 16.08(7 \%), 16.23(8 \%), 16.38(9 \%)$.
\end{abstract}

Keywords Boiler, Steam, hermal Efficiency, Air Fuel Ratio

\section{PENDAHULUAN}

Perkembangan kebutuhan energi saat ini mengalami peningkatan seiring dengan meningkatnya kegiatan pembangunan ekonomi pada suatu negara. Menurut proyeksi Badan Energi Dunia (International Energy AgencyIEA), hingga tahun 2030 permintaan energy dunia meningat sebesar $45 \%$ atau rata-rata mengalami peningkatan sebesar $1,6 \%$ per tahun. Sebagian besar atau sekitar $80 \%$ kebutuhan energy dunia tersebut dipasok dari bahan bakar fosil. Kebutuhan energi dunia terus mengalami peningkatan [1] 
Dalam industri penggunaan boiler sangat dibutuhkan sebagai alat penghasil energi yang akan digunakan sebagai proses produksi. Boiler adalah suatu alat berbentuk bejana tertutup yang terbuat dari baja dan digunakan untuk menghasilkan uap atau steam (Singgih, Agus. 2016) [2]. Uap yang dihasilkan dari boiler ini pada umumnya berasal dari proses pembakaran yang menggunakan bahan bakar gas, cair maupun bahan bakar padat. [3]. Di dalam boiler, energi kimia dari bahan bakar diubah menjadi panas melalui proses pembakaran dan panas yang dihasilkan sebagian besar diberikan kepada air yang berada di ketel, sehingga air akan berubah menjadi uap (steam).

Pada penelitian yang telah dilakukan sebelumnya yaitu membuat boiler jenis pipa air (water tube boiler) yang menggunakan sistem cross section. Sistem cross section ini artinya tube pada boiler disusun secara melintang bertujuan untuk memperluas area tube sehingga luas area perpindahan panas pada boiler menjadi lebih besar kemudian merancang tube dengan kemiringan tube 65 dengan tujuan agar mempercepat penguapan pada molekul air sehingga dapat meningkatkan efisiensi termal pada boiler. Namun pada penelitian sebelumnya terdapat kekurangan yang membuat nilai efisensi termal yang belum mencapai target. Kekurangannya yaitu masih belum memiliki flow meter, blower, dan pompa yang digunakan juga mengalami kerusakan dikarenakan tekanan balik pada boiler yang cukup besar(Apriani, Marsa 2020) [4]

Berdasarkan kekurangan pada penelitian sebelumnya yaitu akan dilakukan pengupgradean pada sistem injection Boiler feed Water dan sistem kontrol secondary udara pembakaran. Pada sistem injection boiler feed water dilakukan perubahan sistem pemompaan yang tahan tekanan balik dan tahan panas. Untuk sistem secondary udara pembakaran akan didukung menggunakan blower dan flow meter sehingga laju pemasokan udara akan terkontrol. Selanjutnya yaitu sistem control level ketinggian air pada drum tujuannya agar air didalam akan tenang dan terbaca oleh alat water level gauge saat proses berjalan. Dengan upgrade ketiga sistem tersebut diharapkan proses produksi steam akan dapat berlangsung secara steady state atau kontinyu.

Bahan bakar yang digunakan harus pada jumlah yang tepat sesuai dengan kebutuhan steam. Umumnya bahan bakar yang digunakan untuk memproduksi steam pada boiler adalah gas, solar, atau batubara. Pada penelitian sebelumnya digunakan bahan bakar berupa solar, dimana solar ini banyak terdapat dampak negatif yaitu seperti pencemaran lingkungan, banyak gas karbondioksida, hujan asam, menyebabkan polusi udara yang membuat lingkungan tidak sehat. Pada penelitian ini, bahan bakar yang digunakan adalah bahan bakar gas berupa gas LPG (Liquified Petroleum Gas). Penggunaan LPG sebagai bahan bakar dilakukan karena pembakaran LPG menghasilkan emisi dan Efek rumah kaca yang rendah (J.Morganti, et al., 2013) [5]. LPG juga diketahui sebagai bahan bakar yang ramah lingkungan, menghasilkan emisi gas buang yang rendah, bebas sulfur dan timbal, nilai angka oktan sangat tinggi lebih dari 98, serta harga gas yang stabil dan tidak terpengaruh oleh harga gas internasional.

\subsection{Boiler pipa air (Water Tube Boiler)}

Boiler pipa air merupakan boiler dimana air umpannya mengalir melalui pipa-pipa masuk ke dalam drum. Air yang tersirkulasi panas pengapian terjadi di luar pipa, kemudian panas yang dihasilkan memanaskan pipa yang berisi air dan sebelumnya air tersebut dikondisikan terlebih dahulu melalui economizer, kemudian uap yang dihasilkan terlebih dahulu dikumpulkan didalam sebuah steam drum. Sampai tekanan dan temperatur sesuai.

Water tube boiler yang sangat modern dirancang dengan kapasitas steam antara $4.500-12.000 \mathrm{~kg} / \mathrm{jam}$, dengan tekanan sangat tinggi. Banyak water tube boiler yang dikonstruksi secara paket jika digunakan bahan bakar minyak bakar dan gas [6]

\subsection{Nilai Kalor Bahan Bakar}

Reaksi kimia antara bahan bakar dengan oksigen dari udara menghasilkan panas. Besarnya panas yang timbulkan jika satu satuan bahan bakar dibakar sempurna disebut nilai kalor bahan bakar (Calorific Value).

Nilai kalor bawah (Low Heating Value) merupakan nilai kalor bahan bakar tanpa panas laten yang berasal dari pengembunan uap air. Umumnya Kandungan hidrogen dalam bahan bakar cair berkisar 15\% yang berarti setiap satu satuan bahan bakar dan 0,15 bagian merupakan hidrogen. Nilai Lhv gas Lpg yaitu 46110 Kj/kg) [7]

\subsection{Excess Air (Udara Lebih)}

Bahan bakar di dalam boiler memerlukan udara dalam jumlah tertentu untuk terjadinya proses pembakaran yang sempurna. Hal ini merupakan "theoretical air" yang diperlukan untuk terjadinya proses pembakaran dalam kondisi yang sempurna

Akan tetapi, karena kondisi yang tidak sempurna di dalam boiler, maka diperlukan udara yang jumlahnya lebih besar dari theoretical air untuk menjamin terjadinya proses pembakaran secara sempurna. Jumlah udara lebih inilah yang disebut "excess air" 
Tabel 1 Excess Air dan $\mathrm{O}_{2}$ optimum pada gas buang berbagai Bahan Bakar [8]

\begin{tabular}{ccc}
\hline Bahan Bakar & Optimum Excess Air \% & Optimum O $_{2}$ pada Stack Gas \% \\
\hline Batubara & $20-25$ & $4-4,5$ \\
Biomassa & $20-40$ & $4-6$ \\
Stoker firing & $25-40$ & $4,5-6,5$ \\
BBM & $5-15$ & $1-3$ \\
Gas Bumi/LPG & $5-10$ & $1-2$ \\
Black Liquor & $5-10$ & $1-2$ \\
\hline
\end{tabular}

\subsection{Efisiensi boiler}

Efisiensi termal boiler didefinisikan sebagai "persen energi (panas) masuk yang digunakan secara efektif pada steam yang dihasilkan". Terdapat dua metode pengkajian efisiensi boiler:

- Metode Langsung: energi yang didapat dari fluida kerja (air dan steam) dibandingkan dengan energi yang terkandung dalam bahan bakar boiler.

- MetodeTidak Langsung: efisiensi merupakan perbedaan antara kehilangan dan energi yang masuk.

Rumusan sederhana dari perhitungan metode langsung adalah sebagai berikut:

$$
\begin{aligned}
\eta f u e l & =\frac{Q \text { steam }}{\text { Qfuel }} \times 100 \% \\
\eta f u e l & =\frac{Q \times\left(h_{g}-h_{f}\right)}{q \times G C V} \times 100 \%
\end{aligned}
$$

Parameter yang dipantau untuk perhitungan efisiensi boiler dengan metode langsung, yaitu:

- Jumlah Steam yang dihasilkan per jam (Q) dalam Kg/jam

- Jumlah bahan bakar yang digunakan per jam (Q) dalam kg/jam

- Tekanan kerja dalam $(\mathrm{kg} / \mathrm{cm} 2)$

- Suhu air umpan

- Jenis bahan bakar dan nilai panas kotor bahan bakar (GCV) dalam kkal/kg bahan bakar [9]

\section{METODE PENELITIAN}

\subsection{Pendekatan Desain Fungsional}

Pengupgradean rancangan bangun pada cross section water tube boiler terdiri dari delapan unit utama, yaitu steam drum, feed water drum, furnace, superheater tube, water tube, burner, pompa, dan compressor. Selain itu, boiler juga dilengkapi dengan beberapa instrument pendukung, diantaranya pressure indicator, temperature indicator, safety valve, water level gauge, valve, drain valve, dan lain-lain

\subsection{Pendekatan Desain Struktural}

Cross section water tube boiler dirancang dengan beberapa unit yang tergabung menjadi suatu sistem yang terintegrasi. Boiler tersebut tersusun dari dua buah drum, yaitu feed water drum dari steam drum yang terhubung dengan water tube serta superheater tube yang berfungsi sebagai tempat pemanasan air umpan dan uap air. Bahan kontruksi drum terbuat dari baja karbon. Water tube dan superheater tube terbuat dari pipa minyak dengan SCN 40 yang tahan pada kondisi suhu dan tekanan tinggi. Selain itu, terdapat pompa yang berfungsi untuk mengalirkan air umpan boiler. Pompatersebut merupakan pompa sentrifugal, dengan konsumsi daya motor 0,43 kW, tekanan maksimum 146 bar dan aliran fluida 40 liter/menit. Penggunaan pompa sentrifugal tekanan tinggi tersebut dikarenakan proses mengalirkan air umpan boiler memerlukan tekanan yang tinggi untuk melawan tekanan tinggi steam yang ada dalam sistem boiler. Suplai udara primer pembakaran pada burner berasal dari kompresor dengan kapasitas tekanan maksimum 8 bar.

Adapun gambar teknik rancang bangun water tube boiler sebelum upgrade dan sesudah upgrade pada Gambar 1 dan Gambar 2 dibawah ini 


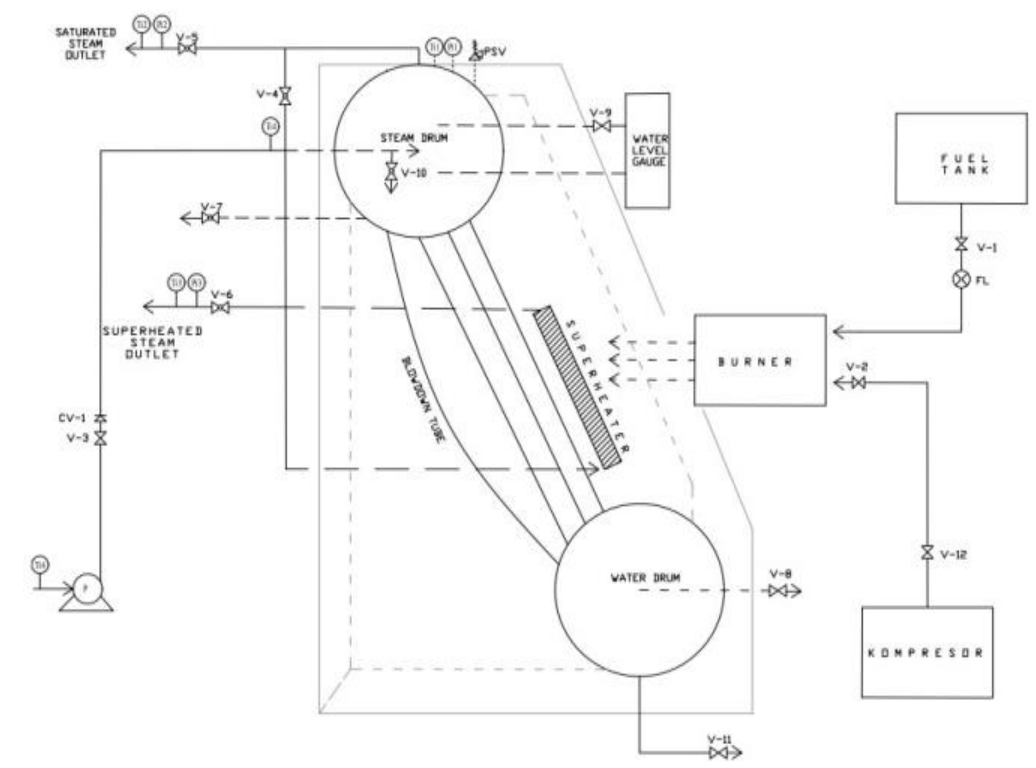

Gambar 1. Gambar Teknik Rancang Bangun Water Tube Boiler sebelum diupgrade

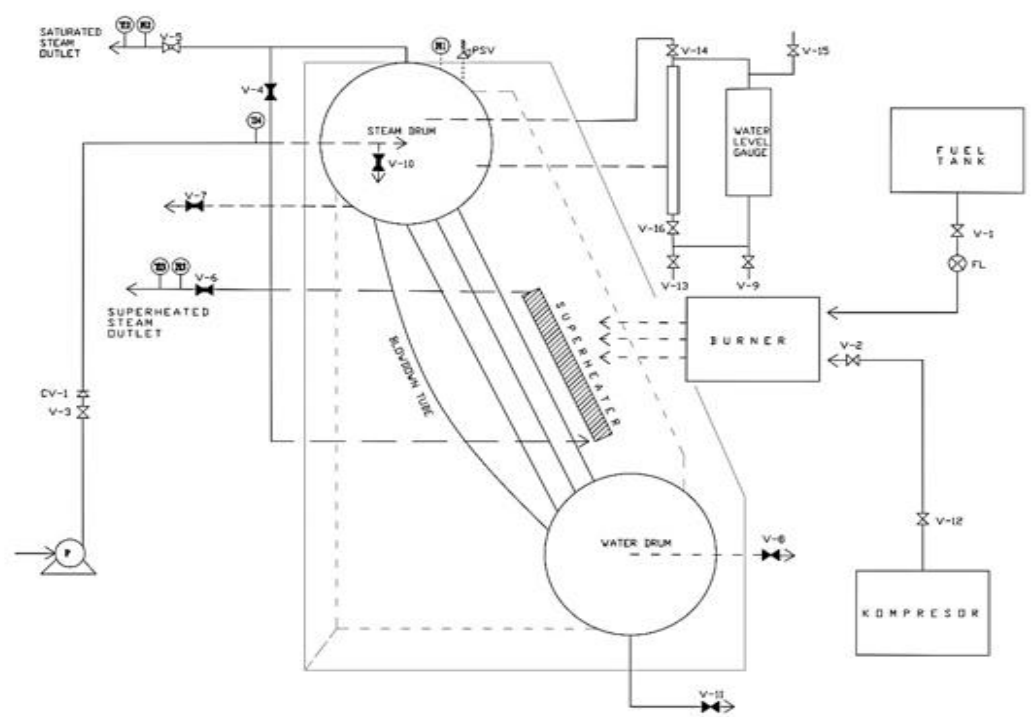

Gambar 2. Gambar Teknik Rancang Bangun Water Tube Boiler sesudah diupgrade

\section{Langkah Pengaturan Pengoperasian}

- Memastikan boiler sudah siap untuk dioprasikan

- Menyiapkan bahan bakar gas dan set kompresor

- Melakukan pengaturan-pengaturan operasi perbedaan rasio udara bahan bakar solar dengan setting sesuai yang dikehendaki, sehingga operasi dapat berlangsung dengan effisiensi yang maksimum.

- Setelah proses pengisin feed water, ventilasi udara dan pembakaran boiler

- siap dioperasikan dalam keadaan staedy state

- Setelah tekanan mencapai 10 bar proses non steady state selesai dan masuk ke keadaan steady state proses continue

- Pada pengoperasian steady state untuk mengambil data saturated steam valve (V-05) dibuka secara perlahan sampai menghasilkan steam sebanyak $5 \mathrm{~L} / \mathrm{jam}$, selanjutnya valve (V-03) dan (V-10) dibuka untuk menyuplai air. Air yang disuplaiakan sesuai dengan jumlah steam yang di keluarkan dilihat dari level volume (LV-01)

- Jika kondisi pengoperasian telah stabil maka lakukan pencatatan terhadap data-data yang diperlukan seperti 
tekanan (PI-02) dan temperatur (TI- 01) pada beberapa unit peralatan lainnya pada matrik yang telah di tentukan

- Mengulang percobaan dengan rasio udara bahan bakar yang berbeda, sesuai dengan rasio udara bahan bakar yang telah ditentukan

- Setelah itu mematikan proses unit steam power sesaui dengan SOP.

- Lakukan analisa hasil percobaan dan lakukan perhitungan laju produksi yang didapatkan.

\section{Shut Down Boiler}

Sebelum menghentikan proses pengoperasi kita harus memastikan bahwa steam sudah tidak digunakan lagi.

- Untuk menghentikan proses pengoperasian yang pertama dilakukan menutup suplay bahan bakar pada burner (V-01).

- Menghentikan suplay udara pada burner dengan mematikan kompressor atau menutup valve (V-02) pada kompressor- Membuka

- valve pada satureated steam (V-05) sampai tekanan 0 bar dan temperatur $35^{\circ} \mathrm{C}$ atau kondisi ruang.

- Setelah boiler dalam kondisi normal dibuka valve (V-07) dan (V-08) untuk mengeluarkan air dalam boiling drum. Jika air pada boiler telah dikeluarkan tutup kembali seluruh valve, Sehingga boiler siap dioperasikan kembali.

\section{HASIL DAN PEMBAHASAN}

Pada penelitian kali ini kali ini dilakukan pengupgradean alat water tube boiler. Penelitian ini dilakukan untuk mengetahui efisiensi termal berdasarkan rasio udara bahan bakar $(A F R)$ yang digunakan untuk memproduksi saturated steam dan superheated steam dengan proses steady state.

\section{1. fisiensi termal pada saturated steam}

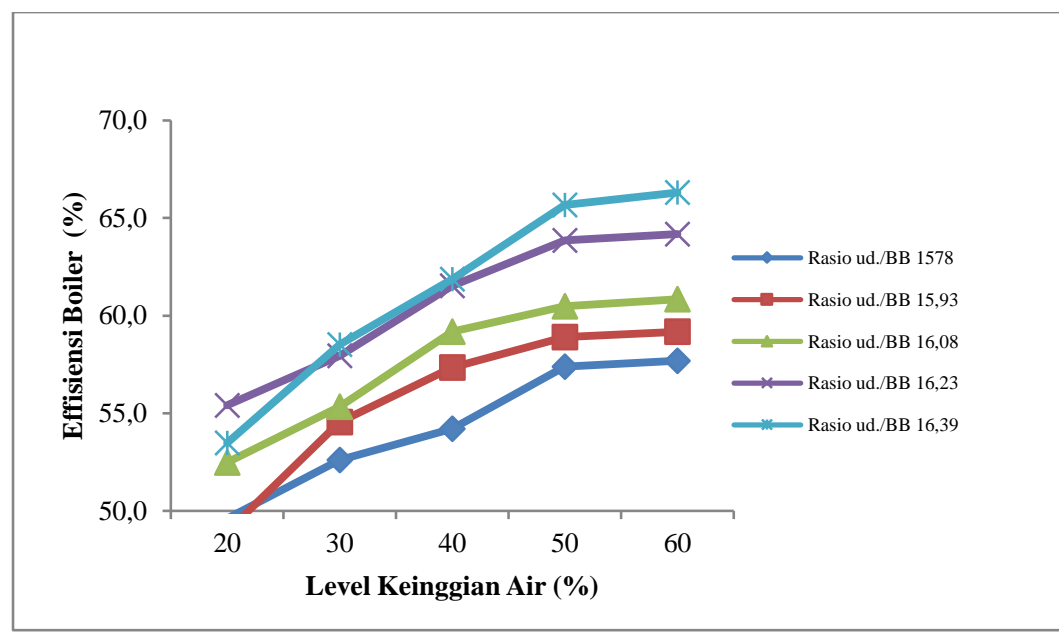

Gambar 3 Grafik Hubungan Rasio Udara/BB gas dan Level Ketinggian (\%) terhadap efisiensi termal $\left({ }^{\circ} \mathrm{C}\right)$

Berdasarkan nilai efisiensi termal yang didapat pada rasio udara bahan bakar dan level ketinggian yang telah ditentukan berbanding lurus dengan efisiensi termal yang dihasilkan water tube boiler. Artinya, semakin tinggi rasio udara bahan bakar dan level ketinggian air, maka efisiensi termal yang dihasilkan akan semakin besar.

Dapat dilihat alur grafik efisiensi termal mengalami kenaikan secara signifikan pada penambahn jumlah udara rasio udara bahan bakar 16,23 dan penambahan level ketinggian hingga 50\%. hal ini dikarenakanpenambahan level ketinggian tersebut mengakibatkan kenaikan jumlah panas yang diterima fluida steam sehingga meningkatkan jumlah kalor yang terserap dan efisiensi termal meningkat. Namun, pada rasio udara bahan bakar 16,38 dengan $\mathrm{O}_{2}$ excess sebesar 9\%, kenaikan efisiensi termal tidak terlalu signifikan. Hal ini dikarenakan temperature saturated steam yang dihasilkan hanya naik $1^{\circ} \mathrm{C}$ dari rasio udara bahan bakar 16,23 , sehingga kenaikan kalor yang termanfaatkan hanya sedikit dan menyebabkan kenaikan efisiensi termalnya kecil.

Berdasarkan hasil yang didapatkan, dapat disimpulkan bahwa efisiensi termal optimal dari water tube boiler terdapat pada rasio udara bahan bakar 16,23 yaitu sebesar 63,9\%. Artinya, rasio udara bahan bakar optimal untuk pembakaran LPG pada pembentukan saturated steam menggunakan cross section water tube boiler ini adalah 16,23 dengan $\mathrm{O}_{2}$ excess $8 \%$. 


\subsection{Efisiensi termal pada superheated steam}

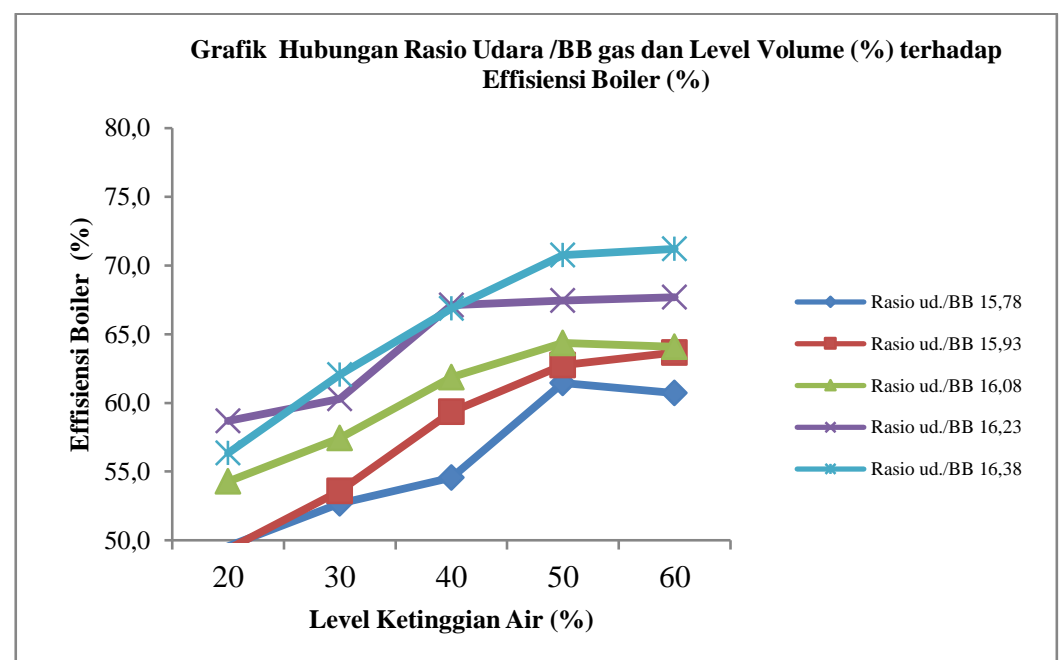

Gambar 4 Grafik Hubungan Rasio Udara/BB gas dan Level Ketinggian (\%) terhadap efisiensi termal $\left({ }^{\circ} \mathrm{C}\right)$

Rasio udara bahan bakar atau (Air Fuel Ratio / AFR) adalah rasio massa udara untuk bahan bakar yang digunakan pada pembakaran boiler. AFR bertujuan untuk menghasilkan suatu pembakaran yang sempurna. Untuk menghasilkan pembakaran yang sempurna diperlukan jumlah udara yang optimal. Udara yang terlalu sedikit akan mengakibatkan pemborosan bahan bakar, karena tidak semua bahan bakar yang digunakan terbakar dan menjadi energi. Sedangkan jika udara yang digunakan terlalu banyak akan menyebabkan pembakaran yang tidak sempurna. Hal ini disebabkan karena kelebihan oksigen dan nitrogen akan menyebabkan terserapnya energi dalam pembakaran dan sisa gas buang melewati stack gas, sehingga sebagian energi yang dihasilkan akan terbuang dan menyebabkan tekanan operasi menurun.

Berdasarkan alur grafik, nilai efisiensi termal yang didapatkan pada range rasio dan level ketinggian yang telah ditentukkan berbanding lurus dengan efisiensi termal yang dihasilkan water tube boiler. Semakin tinggi rasio udara bahan bakar maka efisiensi termal yang akan didapat akan semakin tinggi. Dan juga apabila semakin tinggi level ketinggian air maka efisiensi termal yang dihasilkan akan meningkat pula.

Berdasarkan alur grafik yang ditunjukkan peningkatan rasio udara bahan bakar memberikan pengaruh signifikan terhadap distribusi efisiensi termal. Efisiensi termal yang paling optimal yaitu 64,3\% didapat pada rasio ke-4 dengan jumlah rasio udara bahan bakar 16,23.

Rasio udara bahan bakar tidak boleh terlalu tinggi, namun juga tidak boleh terlalu rendah. Jumlah udara minimum yang diperlukan untuk menghasilkan pembakaran sempurna disebut sebagai jumlah udara stoikiometri. Akan tetapi, pada kenyataannya untuk pembakaran dibutuhkan udara melebihi jumlah udara teoritis. Kelebihan udara teoritis disebut dengan excess air. Efisiensi pembakaran akan meningkat seiring dengan peningkatan jumlah excess air hingga pada nilai tertentu.

\section{KESIMPULAN}

Rasio udara bahan bakar atau disebut Air Fuel Ratio (AFR) merupakan rasio massa udara terhadap bahan bakar padat, cair atau gas yang ada dalam proses pembakaran.

Efisiensi termal yang didapatkan pada saturated steam sebesar $63 \%$ sedangkan superheated steam sebesar $67 \%$ yang didapat pada rasio ke-4 dengan jumlah rasio udara bahan bakar 16,23

\section{DAFTAR PUSTAKA}

[1] N. M. Susantini dan Oktariani, R, "Pemanfaatan Sludge dengan Campuran Black Liqour dan Tempurung Kelapa sebagai Bahan Pembuatan Biobriket,” J. Appl. Sci. JAPPS, vol. 3, no. 1, hlm. 11-19, 2021.

[2] A. Sugiharto, "Tinjauan Teknis Pengoperasian Dan Pemeliharaan Boiler," Swara Patra, vol. 6, no. $2,2016$.

[3] A. Sugiharto, "Perhitungan Efisiensi Boiler dengan Metode Secara Langsung," PPSDMMIGAS Cepu, hlm. $1-6,2020$.

[4] M. Apriani, "Pengaruh Rasio Udara Bahan Bakar Lpg Terhadap Flame Temperature Dan Efisiensi Termal Cross Section Water Tube Boiler Pada Produksi Saturated Steam," Politeknik Negeri Sriwijaya, Palembang, 2020. 
[5] K. J.Morganti Foong, T. M., J.Brear, M.,Silva, G.d., Yang, Y., \& L.Dryer, dan F, The Research and Motor Octane Numbers of Liquefied Gas (LPG). Fuel, 2013.

[6] UNEP, "Bahan Bakar dan Pembakaran”, [Daring]. Tersedia pada: http://www.eneryefficienciasia.org

[7] S. Sudarno dan Fadelan, F, "Peningkatan Efisiensi Kompor LPG Dengan Menggunakan Reflektor Radiasi Panas Bersirip," Semesta Tek., vol. 18, no. 1, hlm. 94-105, 2015.

[8] S. Winarto, "Penghematan energi pada sistem boile," Swara Patra, vol. 4, no. 2, 2014.

[9] W. S. Winanti dan Prayudi, T, "Perhitungan Efisiensi Boiler pada Industri Industri Tepung Terigu," J. Tek. Lingkung., hlm. 58-65, 2006. 